\section{pH-Wert im Urin}

W. G. Guder

München, Deutschland

Englischer Begriff urine $\mathrm{pH}$

Definition $\mathrm{pH}-$ Wert im Blut.

Funktion - Pathophysiologie Die Niere stellt den pH-Wert des Bluts nach den Bedürfnissen des Säure-Basen-Zustands im Blut ein. Dazu dienen Bicarbonatrückresorption, $\mathrm{H}^{+}$-Sekretion und andere Kationensekretionsvorgänge (z. B. $\mathrm{NH}_{4}{ }^{+}$) und Anionentransporter sowie deren Steuerung durch Aldosteron, Angiotensin II und PTH. Bei Störungen dieser Funktionen kommt es zur renal-tubulären Azidose mit inadäquater Anpassung der renalen Säureausscheidungsraten. Darüber hinaus ändert sich der Urin-pH durch postrenale Metabolisierung des Harnstoffs zu Ammoniak durch bakterielle Infektion oder Kontamination.

\section{Untersuchungsmaterial - Entnahmebedingungen Mor- genurin, Mittelstrahlurin.}

Analytik Meist durch $\triangleright$ Teststreifen, nur im Zusammenhang mit wissenschaftlichen Untersuchungen mit pH-Elektrode.
Konventionelle Einheit $\mathrm{H}^{+}$-Konzentration als negative Potenz ohne Dimension $=\mathrm{pH}$.

Internationale Einheit $\mathrm{nmol} / \mathrm{L}-\mathrm{mmol} / \mathrm{L}$ (nicht angewendet, da auch pH SI-konform).

\section{Referenzbereich - Erwachsene 4,5-8.}

Referenzbereich - Kinder Neugeborene 5-7.

Indikation Im Rahmen der Basisuntersuchung von Urin mit Teststreifen, bei Abklärung einer metabolischen Acidose im Kindesalter gemeinsam mit Blutplasma-pH unter Belastung.

Interpretation Bei gemischter Ernährung ist der Urin leicht sauer, bei vegetabiler Ernährung Tendenz zum alkalischen. Nur frisch gewonnener Urin ist aussagekräftig, da rasch Alkalisierung durch Ammoniakbildung in vitro erfolgt.

Diagnostische Wertigkeit Gering.

\section{Literatur}

Guder WG (2009) Harnstatus. In: Guder WG, Nolte J (Hrsg) Das Laborbuch für Klinik und Praxis. Elsevier/Urban und Fischer, München, S 811-814

Soldin SJ, Rifai N, Hicks JMB (1995) Biochemical basis of pediatric disease, 2. Aufl. AACC Press, Washington, DC 